\title{
Telemedical assessment of the level of energy expenditure in overweight and obese individuals
}

\author{
Tomasz Saran ${ }^{1}$, Jakub Owoc², Alfred Owoc ${ }^{3}$, Iwona Bojar ${ }^{4}$ \\ ${ }^{1}$ Department of General and Neurorehabilitation, Witold Chodźko Institute of Rural Health, Lublin, Poland \\ ${ }^{2}$ College of Public Health, Zielona Gora, Poland \\ ${ }^{3}$ Center for Public Health and Health Promotion, Institute of Rural Health, Lublin, Poland \\ ${ }^{4}$ Department for Health Problems of Ageing, Institute of Rural Health, Lublin, Poland
}

Videosurgery Miniinv 2017; 12 (1): 49-59

DOI: https://doi.org/10.5114/wiitm.2016.64984

\begin{abstract}
Introduction: Increasing the energy expenditure above the elementary level of metabolism by undertaking regular physical activity causes body mass reduction and its maintenance at a healthy level.

Aim: To remote assessment of the level of physical activity in a group of overweight and obese individuals.

Material and methods: The research was conducted in the Department of Rehabilitation at the Institute of Rural Health, Lublin, Poland, and included a group of 514 volunteers of both genders ( $38 \pm 12$ years). The examined group was divided into three subgroups depending on the body mass index (BMI) level (I - normal, II - overweight, III obese). The level of physical activity at home was assessed based of the short version of the International Physical Activity Questionnaire (IPAQ), conducted by means of a mobile application, and was compared with data registered by the accelerometer of a smartphone.

Results: The IPAQ-assessed level of the physical activity expressed in MET-min/week amounted to the following values: group I: $5190.38 \pm 6629.84$, group II: $5099.53 \pm 6380.97$, group III: $3939.31 \pm 4000.73$; and the caloric cost (cal $\times$ week $^{-1}$ ) amounted to: group I: $5825.47 \pm 7512.99$, group II: $\left.7204.09 \pm 9187.96\right)$, and group III: $7002.10 \pm 7296.22$. Registered levels of physical activity (MET-min/week) were lower than IPAQ-assessed: in group I (3741.24 \pm 3958.29$)$, in group II (2447.72 \pm 2156.44$)$ and in group III (1927.42 \pm 1790.85$)(p<0.05)$.

Conclusions: The average values of energy expenditure showed a declining tendency, together with an increase in the BMI. On the other hand, the total weekly caloric cost showed the lowest average values in the group with normal body mass.
\end{abstract}

Key words: telehealth, smartphone, motor activity, body mass index, energy expenditure.

\section{Introduction}

Undertaking regular physical activity ensures an optimal state of health in all spheres of life, influencing not only good physical function, but also mental functioning. It causes body mass reduction and its maintenance at the right level $[1,2]$ by increasing the energy expenditure. Nowadays, bariatric surgery is a recognized method of effective treatment of morbidly obese patients. Bariatric surgery, in comparison with non-surgical treatment, has been proven to have better outcomes in terms of the reduction of body mass index (BMI) and remission of several comorbidities associated with obesity. Within 3-6 months after the surgery a significant decrease in fasting glucose, insulin and triglyceride concentrations in serum was observed [3, 4], which may rapidly decrease the possibility of resolution of the

\section{Address for correspondence}

Tomasz Saran MD, PhD, Department of General and Neurorehabilitation, Witold Chodźko Institute of Rural Health, 2 Jaczewskiego St,

20-090 Lublin, Poland, phone: +48 817184 552, e-mail: saran.tomasz@imw.lublin.pl 
symptoms resulting from metabolic syndrome. Bariatric surgery treatment of morbidly obese patients can improve quality of life and restore the ability to undertake regular physical activity. Since 1995, international organizations such as the World Health Organization (WHO), Fédération Internationale de Médecine du Sport (FIMS), the Committee for the Development of Sport (CDDS), and the United Nations Educational, Scientific and Cultural Organization (UNESCO), alarmed by the low level of physical function and the growing hypokinesis in society, have launched health-oriented promotion of physical activity as the superior aim of the contemporary strategy of public health. This strategy has also been launched by authoritative scientific associations, the European Society of Cardiology, the European Atherosclerosis Society, and the European Society of Hypertension, which indicated that the increase in the level of physical activity is as important as the treatment for hypertension or lipid disorders [5].

In recent years, a considerable decline in physical activity has been perceived, caused by the increase in sedentary lifestyle and improper diet. Both these factors favour the development of obesity, mainly in the developed and developing countries $[6,7]$.

Many epidemiological surveys confirm the influence of a lower level of physical activity on the development of obesity worldwide. The long-standing observations by the Coronary Artery Risk Development In Young Adults (CARDIA) confirm the existence of a strong correlation between longer periods of increased physical activity with a simultaneous decline in BMI [8]. However, a short period of intensive physical training during the cardio-rehabilitation is also effective [9]. The perception of physical activity in overweight and obesity treatment as the 'first projection' of primary and secondary prevention is therefore justified.

\section{Aim}

The main aim of this study was assessment of the level of physical activity and its weekly energy expenditure in a group of overweight and obese individuals by means of the mobile application and dedicated web system.

\section{Material and methods}

\section{Physical activity monitoring system}

Assessment of the daily level of physical activity was conducted according to the after-rehabilitation monitoring system created at the Institute of Rural Health in Lublin (www.imw.lublin.pl). The main aim of the system was to control and motivate people to continue an active lifestyle after conclusion of the rehabilitation programme for low-back pain, and other musculoskeletal disturbances. Volunteers were engaged by physiotherapists, and also had the opportunity to take advantage of the feedback from a group of specialists, including doctors and physiotherapists. Physiotherapists had the opportunity to individually follow their patients at home by means of web software (Figure 1). All volunteers from the Rehabilitation Department received explanations and answers to questions about the telemonitoring system. Consent for medical monitoring and scientific evaluation of anonymous data was expressed by smartphone interface.

The level of physical activity was assessed on the basis of the short version of the IPAQ (average week) that was filled in remotely by all the examined persons, and by continuous processing of data from the accelerometer of a smartphone. The questionnaire included 7 questions concerning the types of physical activity undertaken that are parts of everyday life. Thanks to that procedure, information was collected on the amount of time spent in a sitting position, in movement, and undertaking physical activity at moderate and intensive levels.

The assessed factors were the frequency of undertaking physical activity, its duration throughout the day, and intensity, which facilitated the estimation of weekly physical activity divided into 3 spheres of intensity. The level of intensity of physical effort was determined with the aid of the Metabolic Equivalent, where 1 MET equals the $\mathrm{O}_{2}$ consumption at rest, and amounts to $3.5 \mathrm{ml} \mathrm{O}_{2}$ /kilogram of body mass per minute. The adopted values were 3.3 MET for low frequency effort (e.g. walking), 4 MET for moderate, and 8 MET for intensive physical effort. Assessment of physical activity at moderate and intensive levels was conducted only when efforts lasted at least $10 \mathrm{~min}$. The weekly total level of physical activity was obtained by multiplying the number of days it was undertaken in a week, and the duration of a given activity, by the appropriate MET value separately for every sphere of effort intensity, and by subsequently adding together the obtained results for all levels of physical activity performed in a week (MET-min/week). This facilitated the classification of patients into three categories of physical activity 


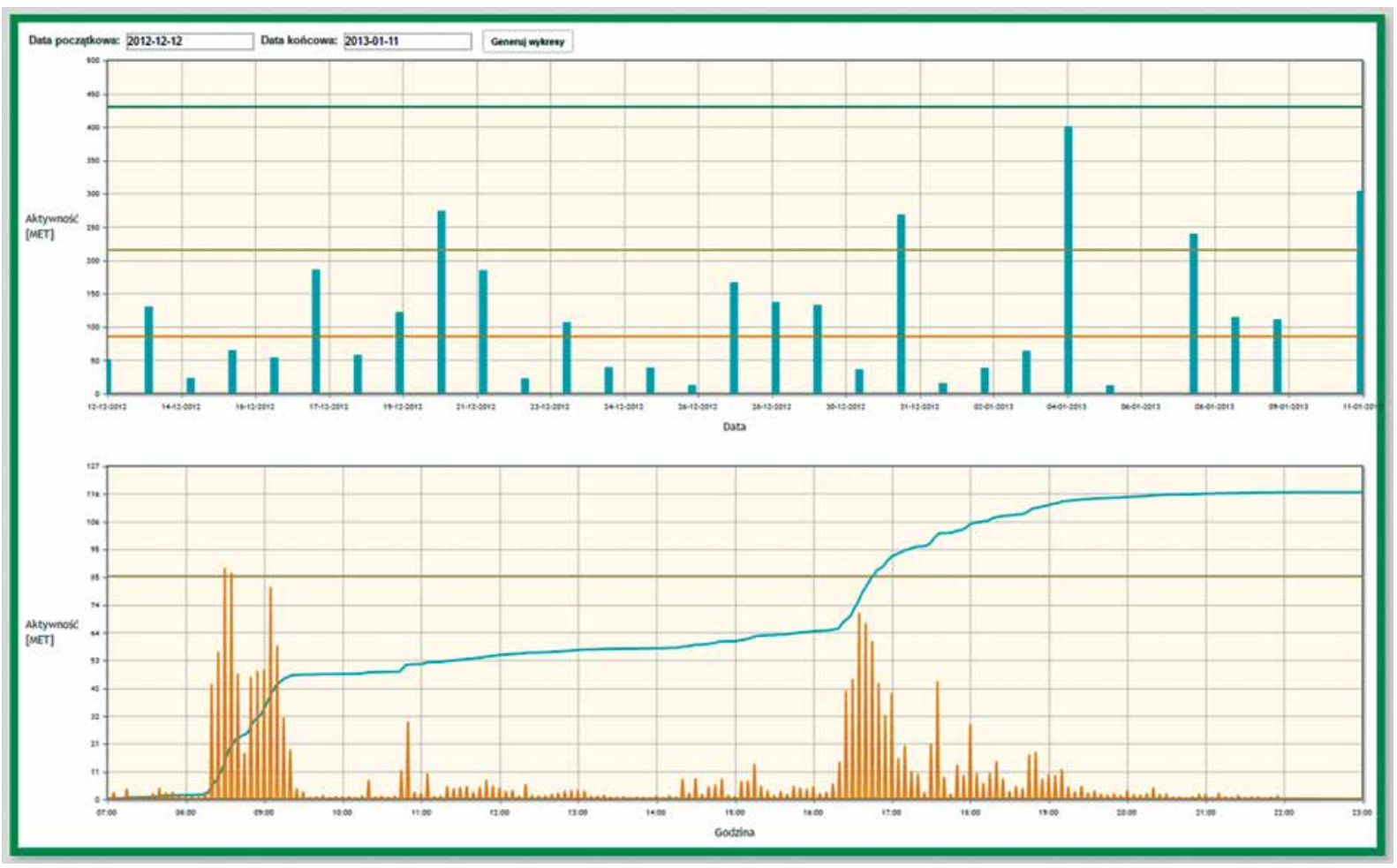

Figure 1. Overall register of motor activity of a patient/user (processed accelerometer data, web interface)

and the assessment of its accordance with the basic WHO guidelines for the examined group [10]:

- insufficient physical activity: $\downarrow 600$ MET-min/ week;

- sufficient physical activity: 600-1,500 MET-min/ week; 3 or $\uparrow$ days of intensive (not less than $20 \mathrm{~min} /$ day), 5 or $\uparrow$ days of moderate activity and/or walks (not less than $30 \mathrm{~min} /$ day); a combination of intensive/moderate efforts at least 600 MET-min/week;

- high physical activity: $\uparrow 1500$ MET-min/week; 3 days of intensive effort (not less than $30 \mathrm{~min}$ ), or everyday moderate/intensive activity (at least $30 \mathrm{~min}$ ) exceeding $3000 \mathrm{MET}$-min/week [11].

\section{Caloric cost calculation}

The most accurate reflection of the total weekly energy expenditure is the measurement of its volume, the so-called weekly caloric cost (KAF), calculated as follows $[12,13]: \mathrm{KAF}=\mathrm{TAF} \times 60 \mathrm{~min}^{-1} \times \mathrm{MC}$, where: KAF - weekly caloric cost of physical activity $\left(\right.$ cal $\times$ week $\left.^{-1}\right)$, TAF - weekly volume of physical activity, MC - body mass [kg].

Additional questions facilitated the collection of information on the height and BMI of a given pa- tient, which was then used to calculate the relative $\mathrm{BMI}\left[\mathrm{kg} / \mathrm{m}^{2}\right]$. Assessment criteria for physical activity applied included, as the basis, current health recommendations indicating the regularity of its performance [14].

\section{Accelerometer data processing}

Two types of calibration, static and dynamic, were used in the processing of data obtained from the accelerometer of the smartphone of each user. The static calibration defines the values of gravitational acceleration (measured with the accelerometer) by placing the mobile phone flat on a surface, pushing the measuring button for $3 \mathrm{~s}$, and calculating according to the formula $g=\operatorname{sqrt}\left(x^{2}+y^{2}+z^{2}\right)$ as the mean value of 3 -second measurements, where $x, y, z$ are momentary components of acceleration from the accelerometer. Dynamic calibration facilitated the elimination of differences in sensitivity of accelerometers of various types of smartphones, but primarily restrained differences in places where they were carried during the use of the application. This was done by pushing the button that activates the application, and starting to walk on flat ground for 1 min until receiving the signal of calibration com- 
pletion. The application facilitates control of physical activity undertaken between 7:00 a.m. and 11:00 p.m. Individuals with a history of less than 2 days and $<8 \mathrm{~h}$ a day of application activity were excluded from the analysis.

The most important element of the application is sending a data package once a day to the server of the Institute: the data are presented on collective charts and thus enable secure access to any measurements for the user. Data from the survey and measurements are collected by web software in the form of anonymous records which are available to researchers, but without the possibility of personal identification of the user without consent.

\section{Study group}

A total of 514 individuals of both genders were assigned to the examined group, which was divided into three subgroups depending on the BMI. Group I included 192 individuals with a healthy BMI (18.5$\left.24.9 \mathrm{~kg} / \mathrm{m}^{2}\right)$; average values amounted to $22.60 \pm 1.96$ $\mathrm{kg} / \mathrm{m}^{2}$ (16.30-24.9). Men constituted the majority of this group ( $M-68 \%, F-32 \%)$; average age: 33.29 \pm 11.30 (11.00-72.00). Group II (215 patients) consisted of overweight persons (BMI $\left.-25.0-29.9 \mathrm{~kg} / \mathrm{m}^{2}\right)$, average BMI - $27.13 \pm 1.41 \mathrm{~kg} / \mathrm{m}^{2}(26.90-29.80)$. Group II included $84 \%$ men and $16 \%$ women; average age: $39.15 \pm 11.89$ (16.00-73.00). In group III consisting of 107 patients, the BMI differed significantly from the norm (obesity BMI $\uparrow 30 \mathrm{~kg} / \mathrm{m}^{2}$ ) - average value: $33.44 \pm 3.61 \mathrm{~kg} / \mathrm{m}^{2}$ (30.00-45.60) (Table I; Figure 1). Sixty-nine percent of group III constituted patients with class I obesity (BMI $30-34.9 \mathrm{~kg} / \mathrm{m}^{2}$ ), mainly men ( $M-88 \% ; F-12 \%)$. Body mass index of $35-39.9 \mathrm{~kg} / \mathrm{m}^{2}$ (class II obesity) was observed in $18 \%$ of patients from group III ( $M-84 \%$; F - 16\%). The rest of the group was characterized by the highest level of body mass (class III obesity, BMI $\uparrow 40 \mathrm{~kg} / \mathrm{m}^{2}$ ) and constituted $13 \%$ of group III, mainly men (Figure 2). In all 3 groups, professionally active persons constituted a majority: $76 \%$ in group I, $75 \%$ in group II, and $80 \%$ in group III (Figure 1).

\section{Ethics}

The study was performed in compliance with the World Medical Association Declaration of Helsinki on Ethical Principles for Medical Research Involving Human Subjects. The authors requested the opinion of the Ethics Committee at the Institute of Rural Health and obtained consent for the study.

Table I. Assessment of BMI in examined groups

\begin{tabular}{|c|c|c|c|c|c|}
\hline Variable & Average & Median & Minimum & Maximum & $\begin{array}{l}\text { Standard } \\
\text { deviation }\end{array}$ \\
\hline \multicolumn{6}{|c|}{ Group I $(n=192)$ (normal): } \\
\hline Age [years] & 33.29 & 32.00 & 11.00 & 72.00 & 11.30 \\
\hline Weight [kg] & 68.54 & 69.50 & 42.00 & 93.00 & 10.17 \\
\hline Height $[\mathrm{cm}]$ & 175.01 & 176.00 & 140.00 & 197.00 & 9.48 \\
\hline \multicolumn{6}{|l|}{$\mathrm{BMI}\left[\mathrm{kg} / \mathrm{m}^{2}\right]$} \\
\hline \multicolumn{6}{|c|}{ Group II $(n=215)$ (overweight): } \\
\hline Age [years] & 39.15 & 37.00 & 16.00 & 73.00 & 11.89 \\
\hline Weight [kg] & 85.19 & 85.00 & 40.00 & 116.00 & 9.36 \\
\hline Height [cm] & 177.07 & 178.00 & 125.00 & 200.00 & 8.57 \\
\hline $\mathrm{BMI}\left[\mathrm{kg} / \mathrm{m}^{2}\right]$ & 27.13 & 26.90 & 25.00 & 29.80 & 1.41 \\
\hline \multicolumn{6}{|c|}{ Group III $(n=107)$ (obese): } \\
\hline Age [years] & 41.71 & 39.00 & 24.00 & 77.00 & 10.76 \\
\hline Weight [kg] & 107.01 & 105.00 & 82.00 & 170.00 & 14.53 \\
\hline Height $[\mathrm{cm}]$ & 178.68 & 180.00 & 160.00 & 198.00 & 7.98 \\
\hline $\mathrm{BMI}\left[\mathrm{kg} / \mathrm{m}^{2}\right]$ & 33.44 & 31.90 & 30.00 & 45.60 & 3.61 \\
\hline
\end{tabular}




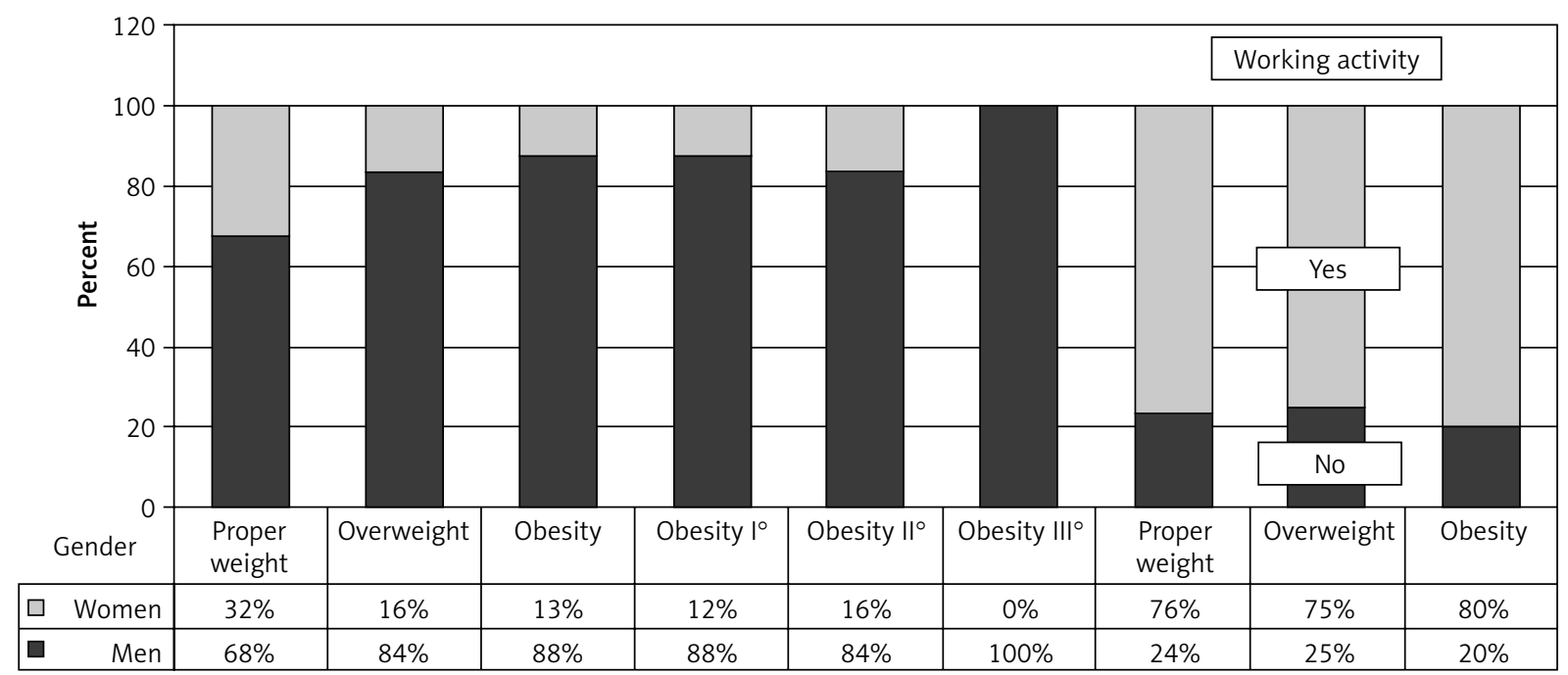

Figure 2. Characteristics of the examined group (BMI, gender, working activity)

\section{Statistical analysis}

Statistical data were gathered using Statistica 12.0 software, elementary descriptive statistics and sign tests.

\section{Results}

According to the IPAQ, the most significant element in the assessment of the level of physical activity is the joint (weekly) energy expenditure (MET$\mathrm{min} /$ week) of different combinations of physical efforts (MET 1 - intensive efforts; MET 2 - moderate efforts; MET 3-walking), and the weekly caloric cost $\left(\mathrm{KAF}\right.$ cal $\times$ week $\left.^{-1}\right)$ of different levels of physical activity (KAF 1 - intensive efforts; KAF 2 - moderate efforts; KAF 3 - walking).

Joint level of physical activity, expressed as MET$\mathrm{min} /$ week for group I: $5190.38 \pm 6629.84$, group II: $5099.53 \pm 6380.97$, and group III: $3939.31 \pm 4000.73$, caloric cost $\left(\mathrm{cal} \times\right.$ week $\left.^{-1}\right)$ : $5825.47 \pm 7512.99$ in group I, group II: $7204.09 \pm 9187.96$, and group III: $7002.10 \pm 7296.22$ (Figure 3). The average values of total energy expenditure showed a declining tendency along with an increase in BMI. The total weekly caloric cost showed the highest average values in groups II and III, and had the lowest values in the group with proper body mass (Figure 4).

The results of the research indicate that according to a subjective assessment, the whole group can be qualified as having 'high' physical activity ( $\uparrow 1500$ MET-min/week), regardless of the BMI. However, taking into consideration the average amount of days and time spent on undertaking different forms of physical activity, the particular groups do not fit into the norms of this level of activity. The characteristic of the high level is undertaking an activity at least $3 / 7$ days, and $3 / 5$ days for the sufficient level. The average number of days of intensive physical effort and its duration (in a week) amounted to 1.95 \pm 1.74 days and $78.05 \pm 88.70 \mathrm{~min}$ in group I, 1.69 \pm 1.74 days and $75.27 \pm 96.71 \mathrm{~min}$ in group $\mathrm{II}$, and $1.31 \pm 1.52$ days and $63.93 \pm 79.82 \mathrm{~min}$ in group III. The average number of days/time of moderate effort in group I was $3.00 \pm 2.31$ days and $105.42 \pm 126.02 \mathrm{~min}$, in group II $2.92 \pm 2.17$ days and $107.47 \pm 121.15 \mathrm{~min}$, and in group III $2.92 \pm 2.11$ days and $98.46 \pm 97.95 \mathrm{~min}$ (Table II).

Results of the research indicate a strong mutual correlation between the weekly energy expenditure (MET-min/week) and the weekly caloric cost (KAF cal

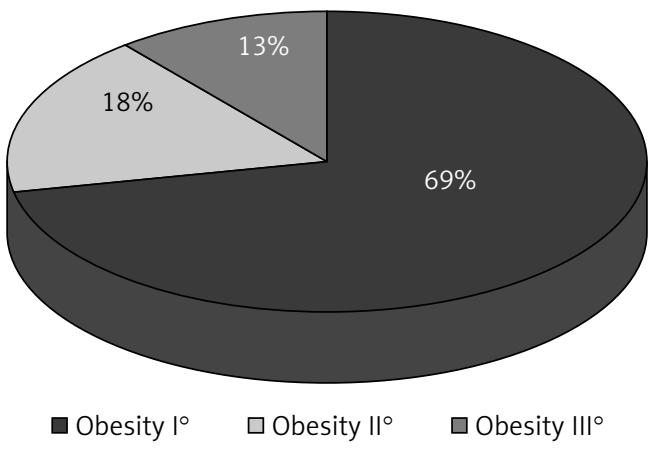

Figure 3. Characteristics of group III depending on obesity class 


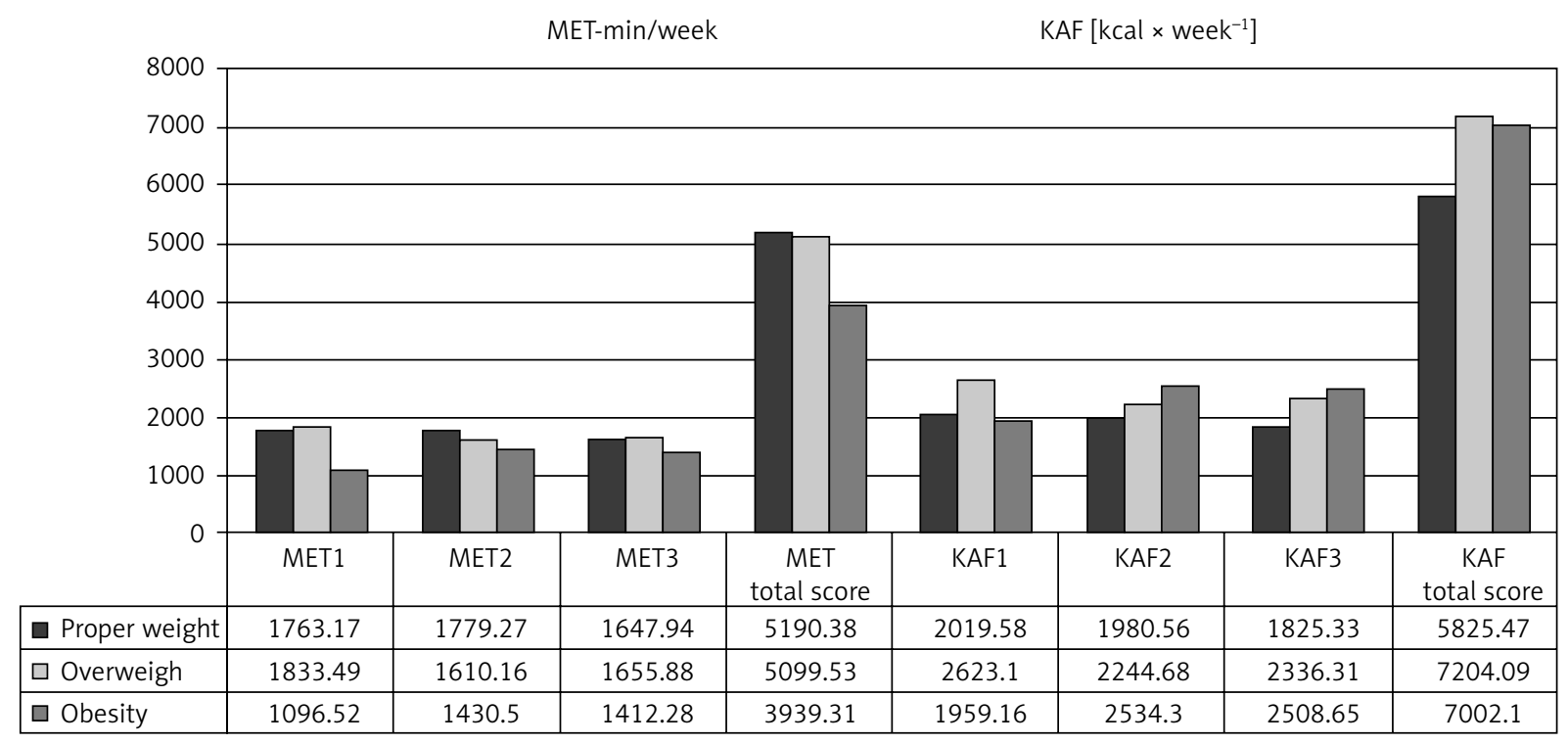

Figure 4. Weekly level of physical activity and its caloric cost depending on the level of physical activity (MET1/KAF1 - intensive efforts, MET2/KAF2 - moderate efforts, MET3/KAF3 - walking)

$\times$ week $^{-1}$ ). During analysis of the results of our research, the $r^{2}$ value was submitted to assessment by statistical analysis, and indicated a mutual correlation between the examined parameters (MET and KAF). The total value of $r^{2}$ in the examined group was 0.9312 , which indicates a $93 \%$ correlation between the examined parameters. The values in the respective groups were as follows: group I KAF/MET $r^{2}=0.9607$ (96\% correlation), group II: KAF/MET $r^{2}=0.9815$ (98\% correlation), and group III: KAF/MET $r^{2}=0.9658$ (96\% correlation) (Figure 5).

The Wilcoxon matched pairs test showed a statistically significant difference between the declared activity (subjective assessment) and the real activity in all examined groups. The declared level of physical activity showed statistically significant differences in relation to the real activity (assessment obtained from the accelerometer of the smartphone) undertaken in all groups, regardless of the BMI. A statistically significant overestimation of the real level of physical activity is observed: in group I, 72.4\% showed a lower level of declared physical activity in relation to the real activity; in group II, it was $73.03 \%$; and in group III it was 71.97\% (Table III).

\section{Discussion}

A sedentary lifestyle or lack of physical activity are two of the main risk factors of obesity, which is a chronic condition developing as a result of an energy balance disorder, i.e. an excess of energy provided to the organism that exceeds the amount of energy expended by the person [6].

Technological advances have had negative influences and resulted in an increase in a sedentary lifestyle, a situation well reflected in everyday life by spending passive leisure time. A person expends around 300 calories per day on physical activity and consumes around 2,100 calories, which results in a proportion of $1: 7$. The daily energy expenditure should be increased by 400 calories through aerobic efforts lasting approximately 45-60 $\mathrm{min} /$ day [6] to equalize the energy balance.

The WHO project 'The European Health Interview Survey' (EUROHIS), which recommends tools for population health measurement, based mainly on physical activity, recommends the application of IPAQ in its short and long versions. The European Physical Activity Surveillance System (EUPASS) emphasizes its advantages as well assessing it as the most advanced international method for evaluating the level of physical activity [15]. Booth even defined it as the only real method facilitating the performance of research on large populations, particularly in developed and developing countries [16]. The short version of the questionnaire was included in the Risk Management Package of WHO (2002/2003) [15]. Our own research made use of the short ver- 
Table II. Assessment of the level of weekly physical activity in examined groups

\begin{tabular}{|c|c|c|c|c|c|}
\hline Variable & Average & Median & Minimum & Maximum & $\begin{array}{l}\text { Standard } \\
\text { deviation }\end{array}$ \\
\hline \multicolumn{6}{|l|}{ Group I $(n=192)$ (normal): } \\
\hline Intensive efforts [days] & 1.95 & 1.50 & 0.00 & 7.00 & 1.74 \\
\hline Intensive efforts [time/min] & 78.05 & 60.00 & 0.00 & 600.00 & 88.70 \\
\hline Moderate efforts [days] & 3.00 & 3.00 & 0.00 & 7.00 & 2.31 \\
\hline Moderate efforts [time/min] & 105.42 & 60.00 & 0.00 & 780.00 & 126.02 \\
\hline Walking [days] & 5.15 & 7.00 & 0.00 & 7.00 & 2.45 \\
\hline Walking [time/min] & 83.99 & 60.00 & 0.00 & 840.00 & 103.88 \\
\hline Sitting [days/time] & 0.00 & 0.00 & 0.00 & 0.00 & 0.00 \\
\hline \multicolumn{6}{|l|}{ Group II ( $n=215)$ (overweight): } \\
\hline Intensive efforts [days] & 1.69 & 1.00 & 0.00 & 7.00 & 1.76 \\
\hline Intensive efforts [time/min] & 75.27 & 60.00 & 0.00 & 600.00 & 96.71 \\
\hline Moderate efforts [days] & 2.92 & 3.00 & 0.00 & 7.00 & 2.17 \\
\hline Moderate efforts [time/min] & 107.47 & 60.00 & 0.00 & 720.00 & 121.15 \\
\hline Walking [days] & 5.30 & 7.00 & 0.00 & 7.00 & 2.26 \\
\hline Walking [time/min] & 81.40 & 60.00 & 0.00 & 600.00 & 104.85 \\
\hline Sitting [days/time] & 0.00 & 0.00 & 0.00 & 0.00 & 0.00 \\
\hline \multicolumn{6}{|l|}{ Group III ( $(n=107)$ (obese): } \\
\hline Intensive efforts [days] & 1.31 & 1.00 & 0.00 & 7.00 & 1.52 \\
\hline Intensive efforts [time/min] & 63.93 & 40.00 & 0.00 & 480.00 & 79.82 \\
\hline Moderate efforts [days] & 2.92 & 2.00 & 0.00 & 7.00 & 2.11 \\
\hline Moderate efforts [time/min] & 98.46 & 60.00 & 0.00 & 480.00 & 97.95 \\
\hline Walking [days] & 5.06 & 6.00 & 0.00 & 7.00 & 2.36 \\
\hline Walking [time/min] & 73.42 & 60.00 & 0.00 & 600.00 & 85.85 \\
\hline Sitting [days/time] & 0.00 & 0.00 & 0.00 & 0.00 & 0.00 \\
\hline
\end{tabular}

sion of IPAQ, which appears to be an 'ideal' tool for assessment of physical activity when combined with the telemedical system (Institute of Rural Health in Lublin), particularly in a group of individuals with overweight and obesity.

During The First Mike Stock Conference in Bangkok (2002) it was established that the everyday undertaking of moderate physical effort (45-60 min) in free time is sufficient for the prevention of overweight and obesity, and 60-90 min are enough for the prevention of subsequent body mass reduction in obese persons [6]. Two years later in Prague, a European project on obesity management, the Man- agement of Obesity in Adults: Project for European Care, was presented. In its subchapter dedicated to physical activity, it included guidelines concerning the necessity for increasing daily physical activity by at least $30 \mathrm{~min} /$ day, regardless of age [17]. The factor assessed in our research was the BMI, which showed a significant deviation from the weight norm in groups II and III. Its average values were $27.13 \pm 1.41 \mathrm{~kg} / \mathrm{m}^{2}$ in group II and $33.44 \pm 3.61 \mathrm{~kg} /$ $\mathrm{m}^{2}$ in group III, while in group I the values did not diverge from the norm $\left(22.27 \pm 1.96 \mathrm{~kg} / \mathrm{m}^{2}\right)$. Persons with BMI indicating class I (69\%), class II (18\%) and class III (13\%) obesity were observed in group III, and 


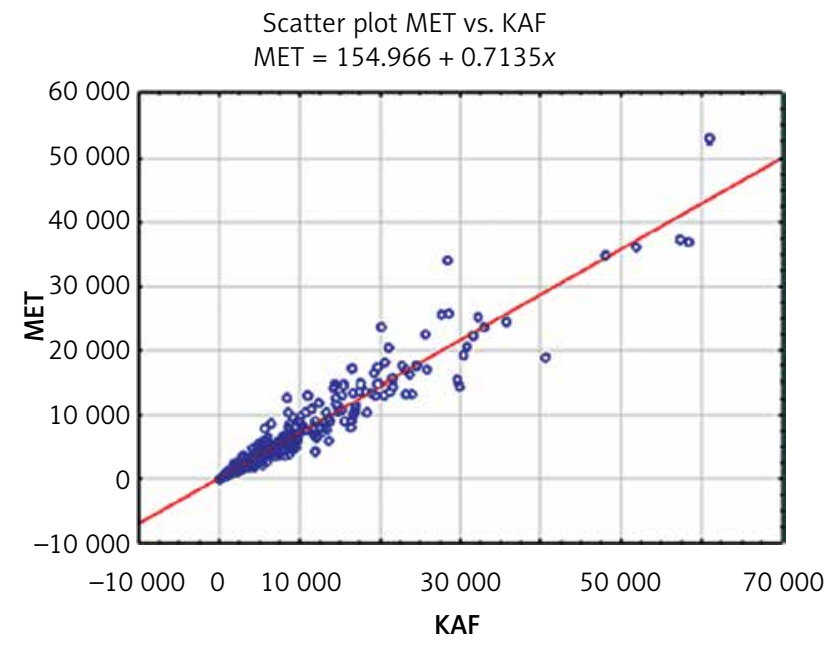

KAF : MET $r^{2}=0.9312$

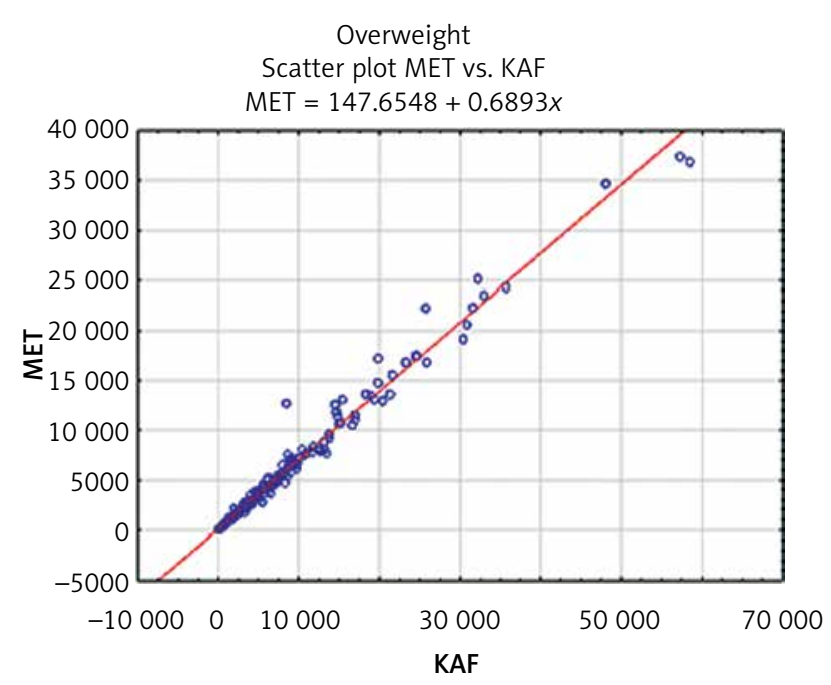

KAF : MET $r^{2}=0.9815$

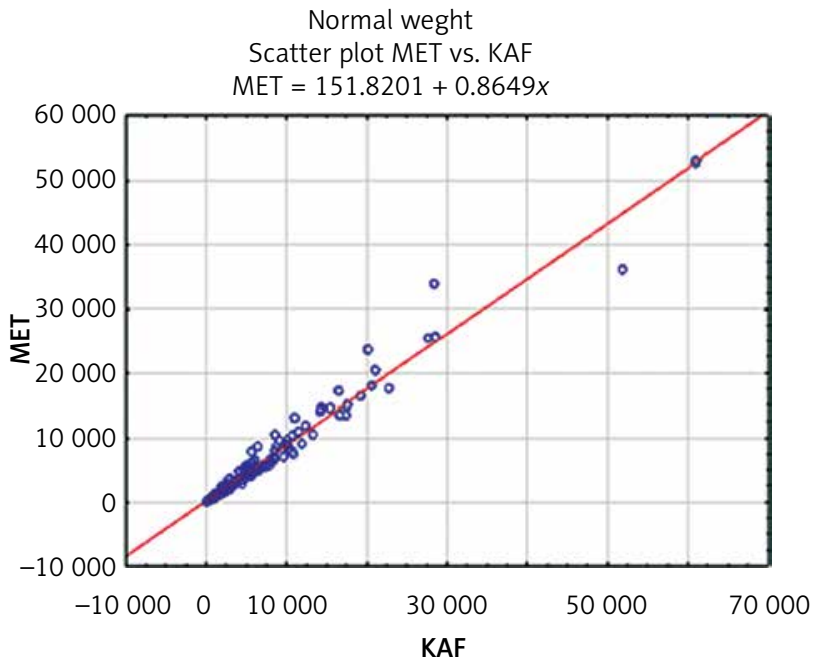

KAF : MET $r^{2}=0.9607$

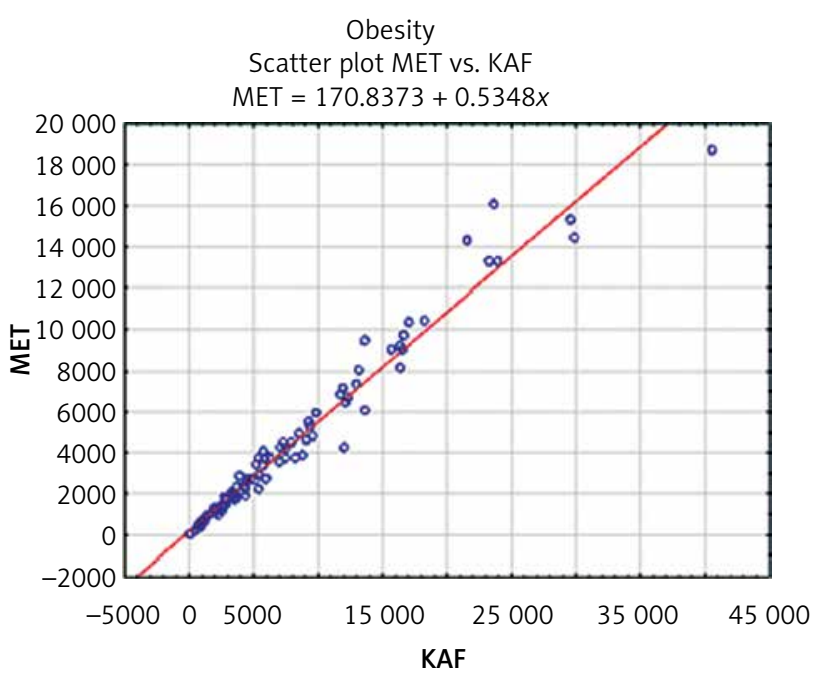

KAF : MET $r^{2}=0.9658$

Figure 5. Dispersion of weekly physical activity (MET) and caloric cost (KAF) in the examined group

this situation is linked with significant health risks due to high BMI values.

According to the guidelines of the WHO on preventing the development of civilization diseases and on health maintenance in the adult group (18-64 years), the undertaking of physical activity at a moderate $(\geq 150 \mathrm{~min} /$ week) or intensive level $(\geq 75 \mathrm{~min} /$ week) is recommended, or a combination of both kinds of physical effort [18]. In the present study, only group I (78.05 $\pm 88.70 \mathrm{~min} /$ week) and group II (75.27 $\pm 96.71 \mathrm{~min} /$ week) fulfilled the above-mentioned requirements related to undertaking activity at an intensive level. The group of obese individuals showed a level beyond the norm of $63.93 \pm 79.2 \mathrm{~min} /$ week. Unfortunately, none of the groups fulfilled the requirements for the time spent on undertaking activity at a moderate level: group I - $105.42 \pm 126.02$, group II $-107.47 \pm 121.15$, and group III -98.46 $\pm 97.95 \mathrm{~min} /$ week.

The IPAQ used in the current study facilitated estimation of the weekly energy expenditure for different levels of physical activity in a given period, which made it possible to assess whether the level of activity is sufficient for preventing secondary overweight and obesity. The level of physical activity enabled the classification of group I and group II patients as those with a 'high' level of activity (1,5003,000 MET-min/week), and group III, patients in the 
Table III. Assessment of real level of physical activity in the examined group

\begin{tabular}{|c|c|c|c|c|}
\hline Variable & $\mathrm{BMI}\left[\mathrm{kg} / \mathrm{m}^{2}\right]$ & Invalid & \multicolumn{2}{|c|}{ Average $\pm S D$} \\
\hline \multirow{3}{*}{$\begin{array}{l}\text { Declared } \\
\text { activities [MET-min/week] }\end{array}$} & Proper weight & 192 & \multicolumn{2}{|c|}{$5190.38 \pm 6629.84$} \\
\hline & Overweight & 215 & \multicolumn{2}{|c|}{$5099.53 \pm 6380.97$} \\
\hline & Obese & 107 & \multicolumn{2}{|c|}{$3939.31 \pm 4000.73$} \\
\hline \multirow{3}{*}{$\begin{array}{l}\text { Real activity } \\
\text { (MET-min/week) } \\
\text { average day } x 7\end{array}$} & Proper weight & 192 & \multicolumn{2}{|c|}{$3741.24 \pm 3958.29$} \\
\hline & Overweight & 215 & \multicolumn{2}{|c|}{$2447.72 \pm 2156.44$} \\
\hline & Obese & 107 & \multicolumn{2}{|c|}{$1927.42 \pm 1790.85$} \\
\hline \multicolumn{5}{|l|}{ Sign test $p<0.05$} \\
\hline Variable & BMI $\left[\mathrm{kg} / \mathrm{m}^{2}\right]$ & Invalid & $\%$ & $Z$ \\
\hline \multirow{3}{*}{$\begin{array}{l}\text { Real activity and declared } \\
\text { activity }\end{array}$} & Proper weight & 192 & 72.4 & 6.134347 \\
\hline & Overweight & 215 & 73.03 & 6.683545 \\
\hline & Obese & 107 & 71.97 & 4.446988 \\
\hline \multicolumn{5}{|c|}{ Wilcoxon matched pairs test $p<0.05$} \\
\hline Variable & BMI $\left[\mathrm{kg} / \mathrm{m}^{2}\right]$ & Invalid & $T$ & $z$ \\
\hline \multirow{3}{*}{$\begin{array}{l}\text { Declared activity and real } \\
\text { activity }\end{array}$} & Proper weight & 192 & 4433.00 & 6.2658 \\
\hline & Overweight & 215 & 4744.00 & 7.5183 \\
\hline & Obese & 107 & 1244.00 & 5.1126 \\
\hline
\end{tabular}

'sufficient' group [11]. Intensive efforts (MET1) were undertaken with the average energy expenditure of $1763.17 \pm 3407.62$ in group I, $1833.49 \pm 3956.79$ in group II, and $1096.52 \pm 2171.62$ MET-min/week in group III. Moderate efforts (MET2) undertaken produced the following average results: 1779.27 \pm 2981.66 in group I, $1610.16 \pm 2391.44$ in group II, and $1430.50 \pm 1929.11$ MET-min/week in group III. Moreover, the results of our research showed that there was a declining tendency among the average values of total energy expenditure, together with the increase in BMI.

According to the guidelines of the WHO and the American College of Sports Medicine, the recommended optimal frequency of undertaking physical activity in adults (18-65 years) should be at least 5 days a week, from moderate (4-6 MET, $\uparrow 30 \mathrm{~min} /$ day) to intensive (> $6 \mathrm{MET}$, at least $20 \mathrm{~min} /$ day). Everyone should undertake (moderate) physical activity at least 3 times a week to maintain health [19, 20]; however, taking into consideration the average number of days of undertaking different types of physical activities, the studied group did not fit within the norms of the level of activity ascribed to par- ticular groups. The characteristic of the high level is the undertaking of any activity on at least 3/7 days, and for the sufficient level 3/5 days [11]. The average number of days of intensive physical effort was 1.95 \pm 1.74 in group I, $1.69 \pm 1.74$ in group II, and $1.31 \pm 1.52$ in group III. The values for moderate physical effort were $3.00 \pm 2.31$ in group I, $2.92 \pm 2.17$ in group II, and $2.92 \pm 2.11$ days in group III. Paffenbarger et al. also recommend undertaking intensive/moderate activity 3 times a week, and efforts of low frequency (e.g. walking) at least 6 times a week [21]. The latter recommendation (MET3) was not fulfilled by any of the 3 groups: I $-5.15 \pm 2.4$, II $-5.30 \pm 2.26$, III $-5.06 \pm 2.36$ days. Overweight and obese individuals showed in their self-reporting a tendency towards overestimating the real level of physical activity, and treated the excess body mass as an essential barrier to limit their physical function [22]. This assumption was also observed in the present study, between the declaration of activity (self-reporting) and the registered activity in all examined groups (assessment taken from the accelerometer of each smartphone). A statistically significant overestimation of the real level of physical activity was also observed. In group I, 
72.4\% showed a lower level of declared physical activity with regards to the real activity, and in groups II and III the percentages were $73.03 \%$ and $71.97 \%$, respectively. A difference between self-reported and the accelerometer-measured level of physical activity was also reported by Dyrstad et al. and Garriguet et al. [23, 24] in controlled trials. In the study by Dyrstad, differences were affected by gender, age, and education, but not by body mass index.

The results of our research also indicate a strong mutual correlation between the weekly energy expenditure (MET-min/week) and the weekly caloric cost (KAF cal $\times$ week $\left.^{-1}\right)$. During analysis of the results of our research, the $r^{2}$ value was subjected to assessment through statistical analysis, and showed a mutual correlation between the examined parameters (MET and KAF). The total value of $r^{2}$ in the examined group was 0.9312 , which indicated a $93 \%$ correlation between the examined parameters. Paffenbarger et al. recommend efforts with a minimum energy expenditure of $2,000 \mathrm{cal} \times$ week $^{-1}\left(300 \mathrm{cal} \times\right.$ week $\left.^{-1}\right)$ for an adult weighing $70 \mathrm{~kg}$ [21]. The average weight in group I was $68.54 \pm 10.17 \mathrm{~kg}$, and the above-mentioned norm was fulfilled only for activity at the intensive level: KAF1 $2019.58 \pm 4177.52 \mathrm{cal} \times$ week $^{-1}$. In group II, due to higher body mass $(85.18 \pm 9.36 \mathrm{~kg})$, values were observed that were sufficient for the caloric cost of all levels of physical activity $(\uparrow 2,000 \mathrm{cal}$ $\times$ week $\left.^{-1}\right)$. In group III (107.01 $\left.\pm 14.53 \mathrm{~kg}\right)$, only the caloric cost of the intensive level of physical activity

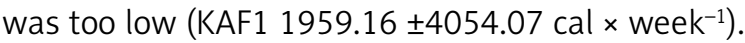

Undertaking regular physical activity plays an important role in primary and secondary prevention of many civilization diseases, e.g. obesity and depression [25]. However, obesity treatment involves dietary approaches, lifestyle intervention, pharmacotherapy, endoscopic intragastric balloon and increasingly bariatric surgery (BMI $\geq 40 \mathrm{~kg} / \mathrm{m}^{2}$ ) [26]. The statement, originating from many research results [27, 28], that physical activity can be treated as the universal way of treatment of body mass disorders seems justified in this study.

\section{Conclusions}

The results of the study indicate a strong mutual correlation between the weekly level of energy expenditure and its caloric cost. The weekly level of energy expenditure shows a declining tendency, together with the increase in BMI. In the examined group, a statistically significant overestimation was observed of the level of physical activity with regards to its registered level, regardless of the BMI.

\section{Acknowledgments}

The study was financed from statutory resources of the IMW.

\section{Conflicts of interest}

The authors declare no conflict of interest.

\section{References}

1. WHO. Diet, Physical Activity and Health: Report by the Secretariat. Fifty-fifth World Health. Assembly, Provisional Agenda Item 13.11, 2002.

2. Harrel JS, McMurray RG, Gansky SA, et al. A public health vS risk-based intervention to improve cardiovascular. Heath elementary school children: The Cardiovascular Health in Children Study. Am J Publ Health 1999; 89: 1529-35.

3. Ruiz-Tovar J, Oller I, Galindo I, et al. Change in levels of C-reactive protein (CRP) and serum cortisol in morbidly obese after laparoscopic sleeve gastrectomy. Obes Surg 2013; 23: 764-9.

4. Jastrzębska-Mierzyńska M, Ostrowska L, Razak Hady H, et al. The impact of bariatric surgery on nutritional status of patients. Videosurgery Miniinv 2015; 11: 115-24.

5. Bijnen FC, Caspersen CJ, Mosterd WL. Physical inactivity as risk factor for coronary heart disease: a WHO and International Society an Federation of Cardiology position statement. Bull WHO 1994; 72: 1-4

6. Saris WHM, Blair SN, van Baak MA. How much physical activity is enough to present unhealthy weight gain? Outcome of the IASO $1^{\text {st }}$ Stock Conference and consensus statement. Obes Rev 2003; 4: 101-14.

7. Biernat E, Tomaszewski P. Association of socio-economic and demographic factors with physical activity of males and females aged 20-69 years. Ann Agric Environ Med 2015; 22: 118-23.

8. Schmitz K, Leon A, Schreiner P, et al. Physical activity and body weight: association over ten years in the CARDIA study. Int J Obes Relat Metab Disord 2000; 24: 1475-87.

9. Szot W, Zając, J, Kostkiewicz M, et al. Cardiac rehabilitation: a good measure to improve quality of life in peri- and postmenopausal women with microvascular angina. Ann Agric Environ Med 2015; 22: 390-5.

10. WHO (2010) Global Recommendations on Physical Activity for Health.

11. Bauman A, Bull F, Chey T, et al. The International Prevalence Study on Physical Activity: results from 20 countries. Int J Behav Nutr Phys Act 2009; 6: 21.

12. Neilson HK, Robson PR, Friedenreich CM, Csizmadi I. Estimating activity energy expenditure: how valid are physical activity questionnaires? Am J Clin Nutr 2008; 7: 279-91.

13. Mahabir S, Baer DJ, Giffen C, et al. Comparison of energy expenditure estimates from 4 physical activity Questionnaire 
with doubly labeled water estimates in postmenopausal women. Am J Clin Nutr 2006; 84: 230-6.

14. Pate RR, Prat M, Blair SN, et al. Physical activity and public health. A recommendation from the centers for Disease Control and Prevention and the American College of Sports Medicine. J Am Med Assoc 1995; 273: 402-7.

15. Craig CL, Marshall AL, Sjøstrom M, et al. International Physical Activity Questionnaire: 12-country reliability and validity. Med Sci Sport Exerc 2003; 35: 1381-95.

16. Booth M. Assessment of physical activity: an international perspective. Res Q Exerc Sport 2000; 71: 114-20.

17. Management of Obesity in Adults: Project for European Medica Care. Int J Obes Relat Metab Disord 2004; 28 (Suppl. 1): 226-31.

18. Global Recommendations on Physical activity for Health: World Health Organisation, Geneva 2010.

19. Haskell WL, Lee IM, Pate RR, et al. Physical activity and public health: updated recommendation for adults from the American College of Sports Medicine and the American Heart Association. Med Sci Sports Exerc 2007; 39: 1423-34.

20. World Health Organization. Global recommendations on physical activity for health 2010.

21. Paffenbarger RS Jr, Hyde RT, Wing AL. Physical activity and physical fitness as determinants of health and longevity. In: Exercise, fitness, and health. Bouchard C, Shephard RJ, Stephens TS, Sutton JR, McPherson BD (eds). Human Kinetics Publishers, Champaign, IL (USA) 1990; 33-48.

22. Ball K, Crawford D, Owen N. Too fat to exercise? Obesity as a barrier to physical activity. Aust N Z J Public Health 2000; 24 331-3.

23. Dyrstad SM, Hansen BH, Holme IM, Anderssen SA. Comparison of self-reported versus accelerometer-measured physical activity. Med Sci Sports Exerc 2014; 46: 99-106.

24. Garriguet D, Tremblay S, Colley RC. Comparison of Physical Activity Adult Questionnaire results with accelerometer data. Health Rep 2015; 26: 11-7.

25. Szalewska D, Skrzypkowska M. Physical activity patterns, depressive symptoms and awareness of cardiovascular risk factors in postpartum women. Ann Agric Environ Med 2016; 23: 502-5.

26. Major P, Stefura T, Jezierska-Kazberuk M, et al. The knowledge of Polish primary care physicians about bariatric surgery. Videosurgery Miniinv 2016; 11: 164-70.

27. Rossner S. Challenges in risk factor management in weight maintenance. Int J Obes Relat Metab Disord 2004; 28 (Suppl. 1): 31.

28. Saris WHM, Schrauwen P. Substrate oxidation differences between high- and low intensity exercise are compensated over 24 hours in obese men. Int J Obes Relat Metab Disord 2004; 28: $759-65$

Received: 25.11.2016, accepted: 18.12.2016. 